\title{
Radioactive Seed Migration after Prostate Brachytherapy with Iodine-125 Using Loose Seeds versus Stranded Seeds
}

\author{
Carlos A. S. Franca, Sergio L. Vieira, Antonio C. P. Carvalho, Antonio J. S. Bernabe, Antonio \\ B. R. Penna
}

Brazilian Institute of Oncology and Radioterapia Botafogo (CASF, SLV, AJSB, ABRP), and Clementino Fraga Filho University Hospital (ACPC), Federal University of Rio de Janeiro, Rio de Janeiro, Brazil

\begin{abstract}
Objectives: To assess the incidence and clinical parameters that could influence migration of seeds in localized prostate cancer patients treated by stranded versus loose sources by Iodine-125 brachytherapy.

Materials and Methods: 100 patients were treated from January/1998 until December/2006. Age, PSA, clinical stage, Gleason, prostate volume, number of seeds, activity of radioactive seeds, and dosimetric parameters, such as $\mathrm{V}_{100}, \mathrm{~V}_{150}$ and $\mathrm{D}_{90}$ were evaluated.

Results: Mean follow-up was 79 months (18 - 120. CI 95\%: 72 - 85). Overall, 6 of 100 patients experienced seed migration. Seed migration was found in 4/50 (8\%) patients using loose seeds and in 2/50 (4\%) treated by stranded seeds. Mean value dosimetric parameters for stranded seeds were greater than those for loose seeds $\left(\mathrm{V}_{100}(\%): 88.7 / 82, \mathrm{D}_{90}(\mathrm{~Gy}): 149.2 / 140.3\right.$, $\mathrm{D}_{90}(\%): 104.2 / 93.8, \mathrm{~V}_{150}(\%): 53.8 / 47$, respectively). No significant difference in migration of seeds was detected between loose and stranded seeds considering age $(\mathrm{p}=0.33)$, PSA $(\mathrm{p}=0.391)$, prostate volume $(\mathrm{p}=0.397)$, activity of radioactive seeds $(p=0.109)$, number of seeds $(p=0.338), V_{100}(p=0.332)$, although significant differences were measured in the values of $\mathrm{D}_{90}(\%$ and $\mathrm{Gy})(\mathrm{p}=0.022$ and 0.011$)$ and $\mathrm{V}_{150}(\mathrm{p}=0.023)$.

Conclusions: Seed migration after brachytherapy might occur and it does affect post-implant dosimetry.
\end{abstract}

Key words: brachytherapy; prostatic neoplasms; seeds; iodine radioisotopes

Int Braz J Urol. 2009; 35: 573-80

\section{INTRODUCTION}

The annual incidence of prostate cancer in Brazil is 52 cases/100.000 (1). Localized prostate cancer (T1-T2) may be treated by external beam radiotherapy (EBRT), radical prostatectomy or brachytherapy (2). Biochemical disease control obtained by brachytherapy with Iodine-125 seeds is similar to radical prostatectomy and EBRT (3). Brachytherapy has gained popularity as a treatment option for early prostate cancer (4), because it is a simple outpatient procedure with low morbidity and good dose target conformity (5). In the USA, brachytherapy is the treatment delivered in $36 \%$ of radiotherapy treatments for prostate cancer (6).

The implantation of radioactive sources in the prostate enables the application of higher radiation doses to the tumor, with better sparing of surrounding tissues (7). An excellent outcome with $85 \%$ prostate-specific antigen (PSA) failure-free survival 
after 10-year follow up and minimum morbidity has been reported in low risk patients (8).

Other benefits of this technique are the short time required to be performed, hospitalization for only 24 hours and low to medium intensity side effects, allowing a quick return of the patient to normal activities (9).

Seed migration is a recognized event in prostate brachytherapy. The reported incidence of seed migration is between $0.7 \%-55 \%$ of patients, and the most common site is to the lungs (4). Seed movement may result in inadequate dosimetry and possible morbidity in distant organs. Because of the rich venous plexus surrounding the prostate, placement of seeds inside or near these vascular structures may result in seed migration (10).

This study assesses the incidence and clinical parameters that influence the migration of radioactive seeds in patients undergoing brachytherapy with stranded or loose sources Iodine-125 seeds, for treatment of localized prostate cancer.

\section{MATERIALS AND METHODS}

This is retrospective study, which analyses 100 patients with localized prostate cancer (T1-T2), referred by different urologists and treated by brachytherapy with Iodine-125 seeds from January/1998 to December/2006.

Brachytherapy is rarely employed in this country due to the locally advanced stage of disease in the majority of patients and the high cost of the radioactive material for a low socio-economic sector of society.

Neoadjuvant hormone therapy with agonist LHRH and/or oral antiandrogens were prescribed by the attending urologist for 2 to 4 months, whenever initial prostatic volume was over $50 \mathrm{~cm}^{3}$, with the purpose of prostate volume shrinkage. No patients received external beam radiotherapy.

Brachytherapy was performed in three sequential stages: preplanning, implantation of radioactive seeds and post-planning dosimetry:

Pre-planning consisted of a volumetric study of the prostate, using a trans-rectal ultrasound (RT fine/3200 Advantage II / RT GE ${ }^{\mathrm{TM}}$ model), equipped with a specific module for prostate brachytherapy. Images of the gland were photographed in equidistant axial planes of $5 \mathrm{~mm}$, from the base to the apex of the prostate and then transferred to a dose planning system (PROWESS 2.0 ${ }^{\mathrm{TM}}$ ), which provides all technical details of the procedure and activity of radioactive seeds needed, measured in milicurie ( $\mathrm{mCi}$ ) per seed. Planned target volume is defined by a $5 \mathrm{~mm}$ margin around anterior and lateral prostate capsule. There is no treatment margin in the posterior prostate surface for rectal protection.

Under epidural anesthesia, seed implantation is performed according to the dose plan, with the aid of a perineal template, under direct transrectal ultrasound vision. Fifty patients were treated with loose seeds (OncoSeed ${ }^{\mathrm{TM}}$ ONCURA.), until December/2000 and 50 used interconnected seeds wrapped in a vycril strand (RAPID Strand ${ }^{\mathrm{TM}}$ ONCURA.), after January/2001. Prescribed doses followed the recommendations of the American Association of Physicists in Medicine (AAPM) Task Group 64 (TG-64) (11), ESTRO/EAU/ EORTC recommendations on prostate brachytherapy (12) and ABS (13) which recommend 145 Gy at the periphery of the gland for isolated brachytherapy with Iodine-125 seeds. Fluoroscopy was performed immediately after completion of the implant to check positioning and distribution of the seed.

Post-planning dosimetry was performed to evaluate the technical quality of the implant and to quantify doses of radiation delivered to prostate, urethra, bladder and adjacent rectum one month after the implant. This procedure begins with a pelvic computerized tomography scan, where the prostate, rectum and bladder were identified, followed by images transference into a computer loaded with PROWESS $2.0^{\mathrm{TM}}$ program, for calculation of final doses of radiation in these organs. Other dosimetric values issued by the computer program are the $\mathrm{V}_{100}, \mathrm{~V}_{150}$ (volume of prostate receiving a minimum of $100 \%$ and $150 \%$ of the prescribed dose) and $\mathrm{D}_{90}$ (Isodose enclosing $90 \%$ of the prostate volume). Criteria for post-implant dosimetric adequacy included a $\mathrm{V}_{100}>80 \%$, a $\mathrm{D}_{90}>$ $90 \%$, and $\mathrm{V}_{150}<60 \%$ for I-125 (14).

Patients treated during the first year of the technique (1997) were also excluded to avoid the learning curve effect interference on the results. Minimum follow-up time was two years. 
Chest, abdomen and pelvic X-rays were taken at the post-planning consultation to search for seed migration and to analyze the technical quality of the implant.

Fuller et al. (15) define migration as the displacement of one or more seeds greater than 1 $\mathrm{cm}$ from the main seed cluster. We adopted a $3 \mathrm{~cm}$ distance from the treatment volume to identify migration of seeds, towards any direction. Patients were examined every four months recording total PSA values and checking clinical and laboratory exams. Patients were discharged home with instructions for filtering their urine and for using preservatives on sexual intercourse during the following three weeks after implantation and to retrieve any eliminated seed.

Pearson's correlation coefficient, Student-ttest, and chi-square analysis techniques were used to determine the strengths of the relationships between biochemical outcome and clinical treatment parameters. A level of significance of $5 \%$ of probability (P $\leq 0.05$ ) and confidence interval with $95 \%$ (CI 95) probability was adopted. SPSS for Windows version 13 (SPSS Inc $^{\mathrm{TM}}$, Chicago, IL, USA) was used for statistical analysis.

This study was approved by the Ethics Research Committee of the Clementino Fraga Filho University Hospital of Federal University of Rio de Janeiro.

\section{RESULTS}

One hundred patients were analyzed and their clinical parameters are listed in Table-1. Mean followup was 79 months (18-120. CI 95\%: 72 - 85).

Migration of seeds was recorded in six patients $(6 \%)$, two cases to the lungs and four to the pelvis, after one or two months follow-up. Chest $\mathrm{X}$-rays showed 3 seeds in one patient and 4 seeds in the other, localized in the lung parenchyma. Pelvic $\mathrm{X}$-rays showed 8 seeds in one case and 2 seeds in the remaining three patients. Table- 2 shows the clinical parameters for each patient with seed migration.

A multivariate analysis of migration between loose and stranded seeds groups is presented in Table3.
No immediate or late side effects were clinically manifested in the lungs or pelvis as a consequence of seed migration to these organs.

No seed migration was detected by the fluoroscopic images during the implant procedure and no urinary seed lost was reported.

\section{COMMENTS}

Seed migration is a well-recognized possibility in prostate brachytherapy. The incidence of seed migration is reported to be between $0.7-55 \%$ of patients (4).

The authors suggest that linked-sources provide best results, because they can be implanted outside the prostate capsule, with low chances to move or migrate (10). Reed et al. (16) showed that patients with stranded seeds have $23 \%$ risk of seeds loss, compared to $47 \%$ incidence in patients receiving loose seeds. Tapen et al. (17) reported that the use of linked seeds in the peripheral needles reduced the incidence of seed migration to $0.7 \%$ compared with the use of free seeds (11\%). Ankem et al. (18) showed that seeds migration may be influenced by the number of implanted seeds alone, whatever the type of seeds used. Sugawara et al. (19) found a correlation between seed migration with more seeds implanted $(p<0.001)$ and increased prostate volume $(\mathrm{p}=0.001)$. This study showed a decrease incidence of migration from 4 to 2 events when connected seeds were used, although this difference was not statistically significant.

Lin et al. (20), Lee et al. (21) and Fuller et al. (15) showed clear improvement in the dosimetric parameters for stranded seeds as compared to loose seeds. Gao et al. (22) and Fuller et al. (21) reported changes in $\mathrm{D}_{90}$ values as result of migration. The greater the numbers of displaced seeds, the lower the value of $\mathrm{D}_{90}$ and $\mathrm{V}_{150}$. On the other hand, the mean values of $V_{100}$ were not affected by migration indicating that $\mathrm{V}_{100}$ was less sensitive to seed migration than $\mathrm{D}_{90}$ and $\mathrm{V}_{150}$. Similar results were obtained in this work where a statistically significance decrease in $\mathrm{D}_{90}$ and $\mathrm{V}_{150}$ values were recorded in patients with seed migration, whereas the $\mathrm{V}_{100}$ values were not significantly changed. Ngyuen (23) reported that seed migration does not cause significant changes in the radiation 
Table 1 - Clinical parameters.

\begin{tabular}{|c|c|c|}
\hline & Loose Seeds & Stranded Seeds \\
\hline Patients & 50 & 50 \\
\hline Age (years) & $\begin{array}{c}68(46-90) \\
\text { CI: } 65.6-70.3\end{array}$ & $\begin{array}{l}67(52-84) \\
\text { CI: } 65-69.4\end{array}$ \\
\hline PSA (ng/mL) & $\begin{array}{l}11.9(4.8-40) \\
\text { CI: } 9.6-14.1\end{array}$ & $\begin{array}{c}9.9(3.4-40) \\
\text { CI: } 7.8-12\end{array}$ \\
\hline \multicolumn{3}{|l|}{ Clinical stage } \\
\hline $\mathrm{T} 1 \mathrm{c}-\mathrm{T} 2 \mathrm{a}$ & $5(10 \%)$ & $14(28 \%)$ \\
\hline $\mathrm{T} 2 \mathrm{~b}-\mathrm{T} 2 \mathrm{c}$ & $45(90 \%)$ & $36(72 \%)$ \\
\hline \multicolumn{3}{|l|}{ Gleason score } \\
\hline $2-6$ & $41(82 \%)$ & $37(74 \%)$ \\
\hline $7-9$ & $9(18 \%)$ & $13(26 \%)$ \\
\hline \multicolumn{3}{|l|}{ Neoadjuvant hormone therapy } \\
\hline No & $22(44 \%)$ & $31(62 \%)$ \\
\hline Yes & $28(56 \%)$ & $19(38 \%)$ \\
\hline Prostate volume $\left(\mathrm{cm}^{3}\right)$ & $\begin{array}{l}36.8(18-75) \\
\text { CI: } 33.3-40.2\end{array}$ & $\begin{array}{l}37.4(12-80) \\
\text { CI: } 34.2-40.7\end{array}$ \\
\hline Numbers of seeds implanted & $\begin{array}{l}100.8(52-136) \\
\text { CI: } 96.3-105.2\end{array}$ & $\begin{array}{c}92.2(59-130) \\
\text { CI: } 88-96.4\end{array}$ \\
\hline $\mathrm{mCi}$ & $\begin{array}{l}0.346(0.260-0.470) \\
\text { CI: } 0.336-0.356\end{array}$ & $\begin{array}{l}0.331(0.280-0.410) \\
\text { CI: } 0.323-0.338\end{array}$ \\
\hline $\mathrm{V}_{100}(\%)$ & $\begin{array}{r}82(52-96.8) \\
\text { CI: } 78.2-85.9\end{array}$ & $\begin{array}{c}88.7(46.2-99) \\
\text { CI: } 83.8-93.6\end{array}$ \\
\hline $\mathrm{D}_{90}(\mathrm{~Gy})$ & $\begin{array}{l}140.3(100-165) \\
\text { CI: } 133.8-146.7\end{array}$ & $\begin{array}{l}149.2(100-186) \\
\text { CI: } 139.6-158.8\end{array}$ \\
\hline $\mathrm{D}_{90}(\%)$ & $\begin{array}{c}93.8(70.1-114.6) \\
\text { CI: } 89.5-98\end{array}$ & $\begin{array}{c}104.2(72.9-129) \\
\text { CI: } 98.1-110.4\end{array}$ \\
\hline $\mathrm{V}_{150}(\%)$ & $\begin{array}{c}47(20.8-64.8) \\
\text { CI: } 42.7-51.2\end{array}$ & $\begin{array}{c}53.8(22.5-68.4) \\
\text { CI: } 49.8-57.8\end{array}$ \\
\hline
\end{tabular}

$C I=$ confidence interval 95\%; PSA = prostate-specific antigen.

planning for the gland because of the relatively small proportion of this event.

The periprostatic venous plexus flanks the prostate gland laterally and anteriorly, and theoretically serves as ready access for radioactive seed embolus, migration of seeds beyond the prostate has been observed fluoroscopically at the time of implantation. It is likely that this migration occurs as a result of seed placement within the large lumens of the periprostatic venous plexus (17). In this study, the migration of seeds was detected only after one or two months of follow-up and there was a concern to implant the least possible number of periprostatic seeds to minimize their displacement.

Although this study showed a decrease in the implant dosimetric values, no clinical consequences could be yet detected. 
Table 2 - Clinical parameters for patients with seed migration.

\begin{tabular}{lcccccc}
\hline & $\mathbf{1}$ & $\mathbf{2}$ & $\mathbf{3}$ & $\mathbf{4}$ & $\mathbf{5}$ & $\mathbf{6}$ \\
\hline Age (years) & 60 & 83 & 70 & 70 & 68 & 73 \\
PSA (ng/mL) & 20 & 5.7 & 7.0 & 40 & 4.4 & 4.0 \\
Clinical stage & $\mathrm{T} 2 \mathrm{C}$ & $\mathrm{T} 2 \mathrm{~B}$ & $\mathrm{~T} 2 \mathrm{C}$ & $\mathrm{T} 2 \mathrm{~B}$ & $\mathrm{~T} 2 \mathrm{C}$ & $\mathrm{T} 2 \mathrm{C}$ \\
Gleason score & 6 & 6 & 4 & 7 & 6 & 7 \\
Prostate volume $\left(\mathrm{cm}^{3}\right)$ & 56 & 35 & 19 & 28 & 41 & 20 \\
Neoadjuvant hormone therapy & $\mathrm{Yes}$ & $\mathrm{No}$ & $\mathrm{No}$ & $\mathrm{Yes}$ & Yes & No \\
Loose $(\mathrm{L})$ or Stranded $(\mathrm{S})$ seeds & $\mathrm{L}$ & $\mathrm{L}$ & $\mathrm{L}$ & $\mathrm{L}$ & $\mathrm{S}$ & $\mathrm{S}$ \\
Number of seeds implanted & 136 & 115 & 104 & 90 & 90 & 78 \\
mCi & 0.26 & 0.34 & 0.32 & 0.34 & 0.34 & 0.31 \\
$\mathrm{~V}_{100}(\%)$ & 78 & 76 & 79 & 77.6 & 90.2 & 80 \\
$\mathrm{D}_{90}(\mathrm{~Gy})$ & 117 & 127 & 115 & 110 & 145 & 140 \\
$\mathrm{D}_{90}(\%)$ & 78.8 & 79.6 & 80 & 77 & 100.7 & 90 \\
$\mathrm{~V}_{150}(\%)$ & 40 & 41.1 & 53.4 & 25.4 & 49.8 & 43 \\
Number of seeds migration & 2 & 2 & 4 & 3 & 8 & 2 \\
Localization of seed migration & Pelvis & Pelvis & Lung & Lung & Pelvis & Pelvis \\
\hline
\end{tabular}

PSA $=$ prostate-specific antigen.

Table 3 - Statistical analysis.

\begin{tabular}{lccccc}
\hline & \multicolumn{2}{c}{$\begin{array}{c}\text { Loose Seeds } \\
\text { Migration }\end{array}$} & \multicolumn{2}{c}{$\begin{array}{c}\text { Stranded Seeds } \\
\text { Migration }\end{array}$} \\
& No & Yes & No & Yes & Significance \\
\hline Patients & 46 & 4 & 48 & 2 & 0.400 \\
Age (years) & 67.7 & 70.7 & 67.1 & 70.5 & 0.330 \\
PSA (ng/mL) & 11.3 & 18.2 & 10.1 & 4.2 & 0.391 \\
Prostate volume $\left(\mathrm{cm}^{3}\right)$ & 36.9 & 34.5 & 37.7 & 30.5 & 0.397 \\
Neoadjuvant hormone therapy & & & & & 0.800 \\
No - number of patients & 20 & 2 & 30 & 1 & \\
Yes - number of patients & 26 & 2 & 18 & 1 & \\
Activity (mCi) & 0.349 & 0.315 & 0.331 & 0.325 & 0.109 \\
Number of seeds implanted & 99.5 & 111.2 & 92.6 & 84 & 0.338 \\
$\mathrm{D}_{90}(\%)$ & 95.7 & 78.9 & 105 & 95.4 & 0.011 \\
$\mathrm{D}_{90}(\mathrm{~Gy})$ & 143.4 & 117.3 & 149.7 & 142.5 & 0.022 \\
$\mathrm{~V}_{100}(\%)$ & 82.5 & 77.6 & 89 & 85.1 & 0.332 \\
$\mathrm{~V}_{150}(\%)$ & 47.9 & 40 & 54.4 & 46.4 & 0.023 \\
\hline
\end{tabular}

PSA = prostate-specific antigen. 


\section{CONCLUSIONS}

In spite of the low number of patients analyzed in this study it can be concluded that seed migration is a possible event that might occur in prostate brachytherapy. The use of stranded seeds resulted in improved post-implant dosimetry compared to the use of loose seeds. Seed migration does affect the implant dosimetry. It is important to perform implants with high technical quality in order to minimize chances of seed migration.

\section{ACKNOWLEDGEMENTS}

Work sponsored by Brazilian Institute of Oncology (IBO). Tereza Cristina da Costa and Pedro Paulo Pereira edited the manuscript.

\section{CONFLICT OF INTEREST}

None declared.

\section{REFERENCES}

1. Instituto Nacional de Câncer (INCA)/MS. Estimativa 2008: Incidência de câncer no Brasil. Rio de Janeiro: INCA; 2007: p33. (Acessed Feb 01, 2009, at http:// www.inca.gov.br/estimativa/2008/versaofinal.pdf)

2. Jani AB, Feinstein JM, Pasciak R, Krengel S, Weichselbaum RR: Role of external beam radiotherapy with low-dose-rate brachytherapy in treatment of prostate cancer. Urology. 2006; 67: 1007-11.

3. Potters L, Morgenstern C, Calugaru E, Fearn P, Jassal A, Presser J, et al.: 12-year outcomes following permanent prostate brachytherapy in patients with clinically localized prostate cancer. J Urol. 2005; 173: 1562-6.

4. Nakano M, Uno H, Gotoh T, Kubota Y, Ishihara S, Deguchi T, et al.: Migration of prostate brachytherapy seeds to the vertebral venous plexus. Brachytherapy. 2006; 5: 127-30.

5. Chen QS, Blair HF: Thyroid uptake of 125iodine after prostate permanent brachytherapy. J Urol. 2004; 172: 1827-9.

6. Nickers P, Thissen B, Jansen N, Deneufbourg JM: 192Ir or 125I prostate brachytherapy as a boost to ex- ternal beam radiotherapy in locally advanced prostatic cancer: a dosimetric point of view. Radiother Oncol. 2006; 78: 47-52.

7. Saito S, Momma T, Dokiya T, Murai M: Brachytherapy for prostate cancer in Japan. Int J Urol. 2001; 8: S227.

8. Okaneya T, Nishizawa S, Nakayama T, Kamigaito T, Hashida I, Hosaka N: Permanent prostate brachytherapy for Japanese men: results from initial 100 patients with prostate cancer. Int J Urol. 2007; 14: 602-6.

9. Franca CA, Vieira SL, Bernabe AJ, Penna AB: The seven-year preliminary results of brachytherapy with Iodine- 125 seeds for localized prostate cancer treated at a Brazilian single-center. Int Braz J Urol. 2007; 33: 752-62; discussion 762-3.

10. Stone NN, Stock RG: Reduction of pulmonary migration of permanent interstitial sources in patients undergoing prostate brachytherapy. Urology. 2005; 66: 119-23.

11. Yu Y, Anderson LL, Li Z, Mellenberg DE, Nath R, Schell MC, et al.: Permanent prostate seed implant brachytherapy: report of the American Association of Physicists in Medicine Task Group No. 64. Med Phys. 1999; 26: 2054-76.

12. Salembier C, Lavagnini P, Nickers P, Mangili P, Rijnders A, Polo A, et al.: Tumour and target volumes in permanent prostate brachytherapy: a supplement to the ESTRO/EAU/EORTC recommendations on prostate brachytherapy. Radiother Oncol. 2007; 83: 3-10.

13. Rivard MJ, Butler WM, Devlin PM, Hayes JK Jr, Hearn RA, Lief EP, et al.: American Brachytherapy Society recommends no change for prostate permanent implant dose prescriptions using iodine- 125 or palladium-103. Brachytherapy. 2007; 6: 34-7.

14. Merrick GS, Grimm PD, Sylvester J, Blasko JC, Butler WM, Allen ZA, et al.: Initial analysis of Pro-Qura: a multi-institutional database of prostate brachytherapy dosimetry. Brachytherapy. 2007; 6: 9-15.

15. Fuller DB, Koziol JA, Feng AC: Prostate brachytherapy seed migration and dosimetry: analysis of stranded sources and other potential predictive factors. Brachytherapy. 2004; 3: 10-9.

16. Reed DR, Wallner KE, Merrick GS, Arthurs S, Mueller A, Cavanagh $\mathrm{W}$, et al.: A prospective randomized comparison of stranded vs. loose 125I seeds for prostate brachytherapy. Brachytherapy. 2007; 6: 129-34.

17. Tapen EM, Blasko JC, Grimm PD, Ragde H, Luse R, Clifford S, et al.: Reduction of radioactive seed embolization to the lung following prostate brachytherapy. Int J Radiat Oncol Biol Phys. 1998; 42: 1063-7. 
18. Ankem MK, DeCarvalho VS, Harangozo AM, Hartanto VH, Perrotti M, Han K, et al.: Implications of radioactive seed migration to the lungs after prostate brachytherapy. Urology. 2002; 59: 555-9.

19. Sugawara A, Nakashima J, Shigematsu N, Kunieda E, Kubo A: Prediction of seed migration after transperineal interstitial prostate brachytherapy with I-125 free seeds. Brachytherapy. 2009; 8: 52-6.

20. Lin K, Lee SP, Cho JS, Reiter RE, DeMarco JJ, Solberg TD: Improvements in prostate brachytherapy dosimetry due to seed stranding. Brachytherapy. 2007; 6: 44-8.
21. Lee WR, deGuzman AF, Tomlinson SK, McCullough DL: Radioactive sources embedded in suture are associated with improved postimplant dosimetry in men treated with prostate brachytherapy. Radiother Oncol. 2002; 65: 123-7.

22. Gao M, Wang JZ, Nag S, Gupta N: Effects of seed migration on post-implant dosimetry of prostate brachytherapy. Med Phys. 2007; 34: 471-80.

23. Nguyen BD: Cardiac and hepatic seed implant embolization after prostate brachytherapy. Urology. 2006; 68: 673.e17-9.

Accepted after revision

March 30, 2009

\section{Correspondence address:}

Dr. Carlos Antônio da Silva Franca

Rua Marechal Niemeyer, 16

Rio de Janeiro, RJ, 22251-060, Brazil

Fax:+ 5521 2266-0449

E-mail: carlosfranca@cremerj.org.br

\section{EDITORIAL COMMENT}

Radiation seed brachytherapy has become established as an excellent curative treatment for early prostate cancer (where urinary flow is reasonable and gland size less than 50-60 cc) with a low side effect profile and good preservation of potency (1-3). The cure rates are equivalent to surgery, equally so for those patients under 60 years of age (4).

The methodology of implantation has evolved since the pioneering work of the Seattle group; our own iterative, per-operative approach of monitoring the actual seed placements and dynamic updating of the plan (with reconfiguration of subsequent seed placement positions) to ensure optimal final distribution is one example (5). Another is the use of stranded seeds. Here, the seeds are inserted into the prostate in 'trains' of 2-5 seeds, separated in space by $1.0 \mathrm{~cm}$; fewer needle passes through the gland are required for each implant and another perceived gain is that seed migration should be less and dosimetry improved.
In the manuscript published here, the authors have analyzed their data with regard to seed migration, important for two reasons - delivering the correct dose to the prostate and avoiding the hazards of depositing radioactive seeds elsewhere in the body. The conclusion is that seed migration is unusual $(6 \%$ in the series reported here). The 4/50 migration rate with loose seeds was not significantly different from the $2 / 50$ with stranded seeds and the study must clearly be extended to larger numbers; other data strongly suggest that stranded seeds reduce the migration rate $(6,7)$ and this would be consistent with the data collected here.

Also of interest to me was the slightly better dosimetry achieved with the stranded seed technique - a conclusion also reached by others $(8,9)$.

Current practice is changing and I would encourage the authors to extend their series to 'firm up' the data. 


\section{REFERENCES}

1. Zelefsky MJ, Kuban DA, Levy LB, Potters L, Beyer DC, Blasko JC, et al.: Multi-institutional analysis of long-term outcome for stages T1-T2 prostate cancer treated with permanent seed implantation. Int J Radiat Oncol Biol Phys. 2007; 67: 327-33.

2. Bottomley D, Ash D, Al-Qaisieh B, Carey B, Joseph J, St Clair S, et al.: Side effects of permanent I125 prostate seed implants in 667 patients treated in Leeds. Radiother Oncol. 2007; 82: 46-9.

3. Taira AV, Merrick GS, Galbreath RW, Butler WM, Wallner KE, Kurko BS, et al.: Erectile Function Durability Following Permanent Prostate Brachytherapy. Int J Radiat Oncol Biol Phys. 2009; 20. [Epub ahead of print]

4. Shapiro EY, Rais-Bahrami S, Morgenstern C, Napolitano B, Richstone L, Potters L: Long-term outcomes in younger men following permanent prostate brachytherapy. J Urol. 2009; 181: 1665-71; discussion 1671.
5. Plowman PN: Recent London improvements in curative radiation therapy for relevant early prostate cancer. Ann N Y Acad Sci. 2008; 1138: 257-66.

6. Al-Qaisieh B, Carey B, Ash D, Bottomley D: The use of linked seeds eliminates lung embolization following permanent seed implantation for prostate cancer. Int $\mathrm{J}$ Radiat Oncol Biol Phys. 2004; 59: 397-9.

7. Reed DR, Wallner KE, Merrick GS, Arthurs S, Mueller A, Cavanagh W, et al.: A prospective randomized comparison of stranded vs. loose 125I seeds for prostate brachytherapy. Brachytherapy. 2007; 6: 129-34.

8. Lee WR, deGuzman AF, Tomlinson SK, McCullough DL: Radioactive sources embedded in suture are associated with improved postimplant dosimetry in men treated with prostate brachytherapy. Radiother Oncol. 2002; 65: 123-7.

9. Lin K, Lee SP, Cho JS, Reiter RE, DeMarco JJ, Solberg TD: Improvements in prostate brachytherapy dosimetry due to seed stranding. Brachytherapy. 2007; 6: 44-8.

Dr. N. P. Plowman

Department of Clinical Oncology St. Bartholomew's Hospital

London, United Kingdom

E-mail: Nick.Plowman@bartsandthelondon.nhs.uk 